Special Issue of the 8th International Advances in Applied Physics and Materials Science Congress (APMAS 2018)

\title{
Finite Element Simulation of Rotary Shaft Lip Seals
}

\author{
B. ENGIN ${ }^{a, b, *}$, İ. SARAÇ ${ }^{a, b}$, AND M. YAZICI $^{b}$ \\ ${ }^{a}$ R\&D Center, SKT Spare Parts and Machinery Industry and Trading Co., Bursa, Turkey \\ ${ }^{b}$ Uludağ University, Engineering Faculty, Automotive Engineering Department, Nilüfer, Bursa, Turkey \\ Radial lip seals operate between stationary machine body and rotating shaft during relative motion under \\ continuously contacting to provide the sealing mechanism. Therefore, the complete modeling of a radial lip seal \\ is very complicated. In this study, a hyperelastic elastomer based radial shaft lip seal mechanical simulations \\ were performed using nonlinear explicit finite element analysis. The finite element analysis results under complex \\ boundary and nonlinear material behavior conditions were obtained and compared with the experimental and \\ theoretical results. According to obtained results, the radial force between the shaft and lip seal of finite element \\ analysis simulation results fully confirms the experimental measurements and the theoretical calculations. perfectly. \\ the obtained differences were less than $1.5 \%$.
}

DOI: 10.12693 /APhysPolA.135.1072

PACS/topics: finite element analysis, radial lip seals, hyperelastic material models, radial load measurement, rubber

\section{Introduction}

Rotary shaft seals are one of the most critical machine parts. They have various industrial applications, including all types of automotive and power-plant machinery, industrial pumps, aircraft gas turbines, powergeneration turbines, and large industrial and pipeline compressors [1]. The function of a rotary shaft seal is to separate pressurized fluids where a moving shaft passes from one part of the machine to another or passes through a machine housing. It can also be used to prevent the entry of the foreign particles into an operating zone or the loss of lubricant from transmissions and bearings. Although a full contact between the seal and the shaft surface supplies perfect sealing, it is not acceptable because of high friction and high wear rate. Well-designed lip seals produce an acceptably low level of leakage with a thin fluid film on moving surface for low friction and low wear rate. The standard rotary shaft seal has a rigid metal insert and a flexible inner lip. Rotary shaft seal lip can be springless or spring loaded. The spring, which is used to build up preloaded between the seal lip and the shaft is called the Garter spring [1].

The researchers have studied finite element analysis (FEA) of the seals due to the very complex working phenomenon and critical machine element [2, 3]. Zhou et al. [2] studied saddle-shaped ring sealing and loadbearing performance are superior to C-ring based on the analysis by using FEM software Abaqus. Yuan and et al. [3] designed a two-dimensional axisymmetric finite element analysis numerical model. They used the MooneyRivlin constitutive model of the rubber material, and the contact penalty function algorithm. Calonius and Pietola [4] evaluated an explicit FEA model, well suited

*corresponding author; e-mail: ismailsarac@skt.com.tr for highly non-linear problems involving frictional contact. It was used to compute the response to the forced relative axial motion of the sealing surfaces.

In this study, the radial load between the seal lip surface and shaft was calculated using analytical, experimental and FEA. The stress and deflection analysis of the seal lip also obtained using FEA simulations.

\section{Materials and method}

The radial load between seal lip and shaft surface can be measured by mechanical, pneumatic or electronic systems. Figure 1 shows the used measurement device. For the accurate measurements, shaft deflections must be very small, and the seal must remain on the machine for 30-60 s until the reading stabilizes [5].

The radial load in a rotary shaft seal is the sum of central acting forces around the seal lip. The radial load is commonly composed of the spring and the sealing element. Figure 2a shows the radial load elements in a rotary shaft seal section. The radial load is calculated by Eqs. (1)-(4) [5]. All characteristic dimensions in these equations can be seen in Fig. $2 \mathrm{~b}$.

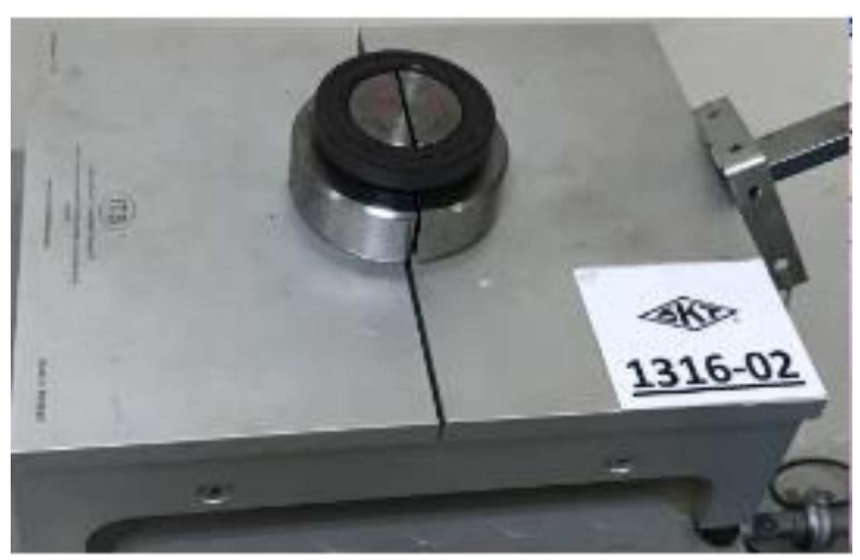

Fig. 1. The radial load measurement device. 

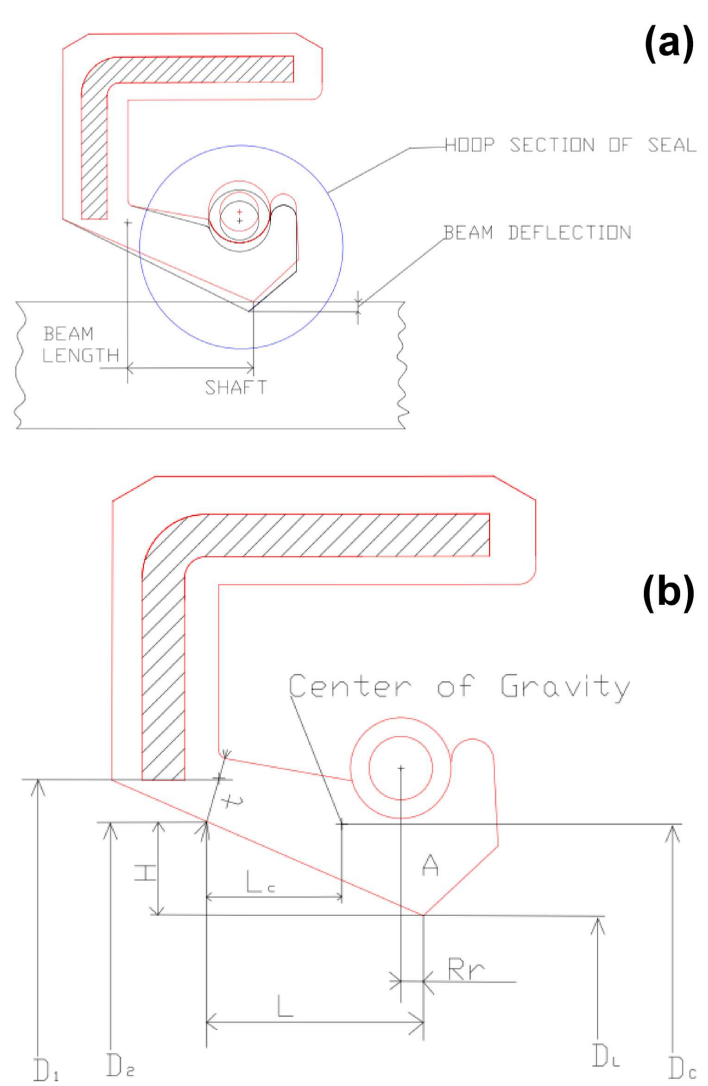

Fig. 2. (a) radial load elements, (b) seal section characteristic dimensions used in the analytical equations.
The spring force:

$$
F_{s}=2 \pi\left(1-\frac{R_{r}}{L}\right) F
$$

The rubber beam deflection force:

$$
F_{B}=\frac{\pi}{8} E_{W} D_{1}\left(D_{S}-D_{L}\right)\left(\frac{t}{L}\right)^{3} C
$$

Rubber hoop force:

$$
F_{R}=2 \pi E_{A} A\left(\frac{D_{S}-D_{L}}{D_{C}}\right)\left(\frac{L_{C}}{L}\right)^{2} C
$$

The total radial force is calculated by the sum of the all above three forces

$$
F_{T}=F_{S}+F_{B}+F_{R}
$$

In these equations, $A$ is the lip cross-section area, and $C$ is the elastomer factor. All dimensions of the seal are given in Fig. 2 and $D_{S}$ is shaft diameter. The $E_{A}$ and $E_{W}$ are the modules of elastomer at $5 \%$ strain (without grain and with grain respectively). The $F$ is the spring tension. For theoretical radial force calculation, Eqs. (1)(4) are implemented in the macro code.

Commonly rubber material used in sealing applications is described as hyperelastic material. In this study, 2D axis symmetrical model in Abaqus was used to define the FEA model, which is composed of two elements: the sealing elastomer and the spring. The seal ring was not defined in the model, but its behavior is defined with boundary condition which was not allowed any displacements in $x$ and $y$ directions (see Fig. 3a). In the analysis, dynamic explicit steps were used.
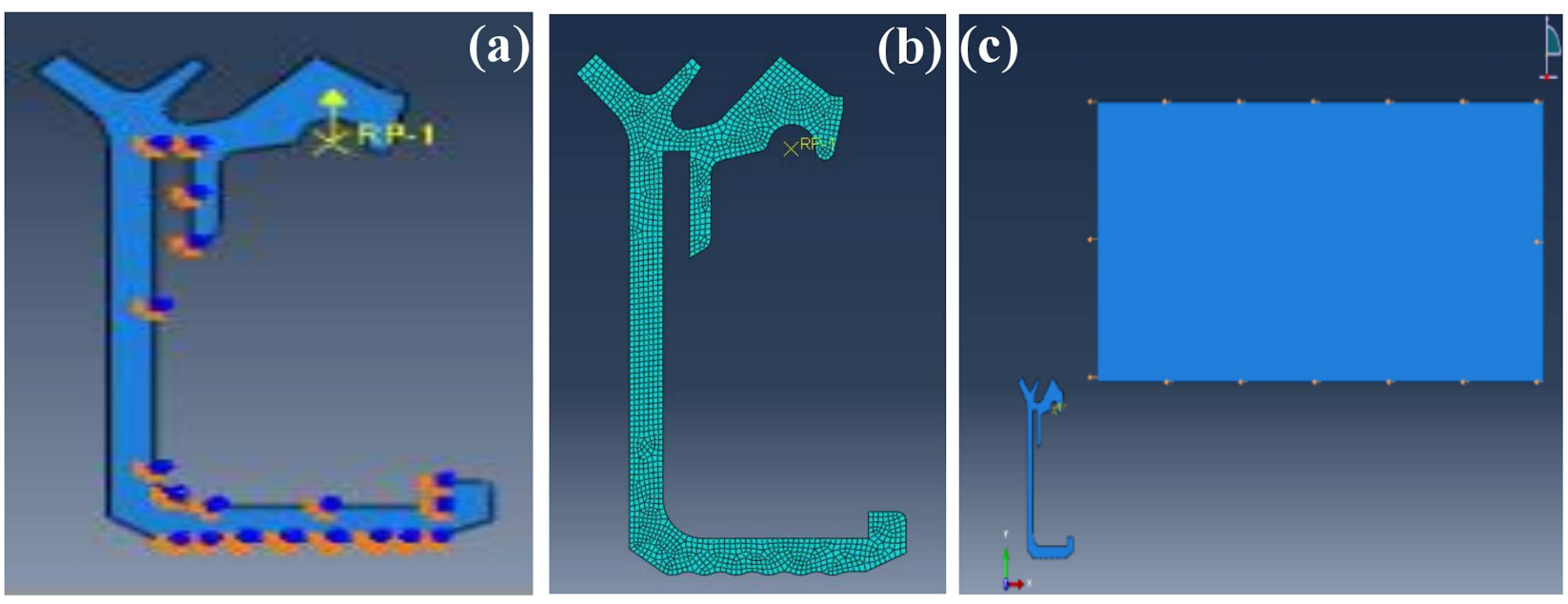

Fig. 3. (a) rotary shaft seal boundary conditions, (b) mesh model of the seal section, (c) motion of the shaft at the seal assembling.

The seal elastomer and the shaft were designed as axisymmetric, deformable and shell models. The spring was defined as an engineering element type, which takes part in Abaqus.

In the FEA 4685 units, linear quadrilateral elements (CPS4R type) were used (see Fig. 3b). The elastomer was defined using the Mooney-Rivlin hyperelastic material model and with $C 10=0.3339, C 01=-0.000337$ and $D 1=0.0015828$ coefficients. The shaft is assembled to seal in a deficient linear motion (see Fig. 3c)

Interactions for FEA model were defined as the surface to surface contact. Contact properties were 0.05 penaltycoefficients of friction for tangential behavior and hard contact, which allows separation after contact for normal behavior. 


\section{Results and discussion}

The theoretical, experimental and FE analysis of radial forces between the seal lip and shaft surface were obtained as $18.0 \mathrm{~N}, 18.3 \mathrm{~N}$, and $18.25 \mathrm{~N}$ respectively. The difference between the FEA and experimental results was obtained as $1.4 \%$. FEA and theoretical calculations for the radial force was obtained as $0.28 \%$.
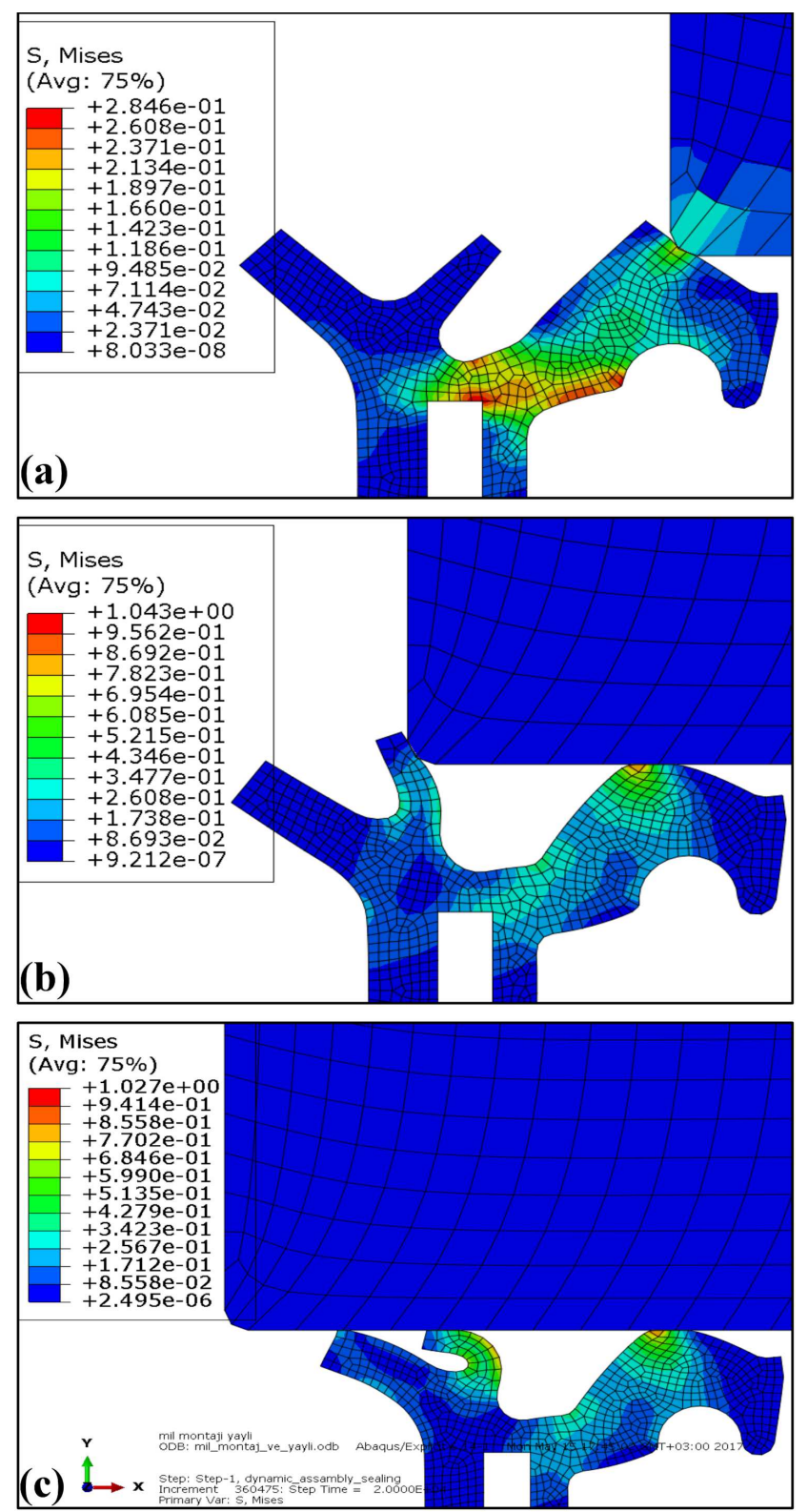

Fig. 4. Contact stress during assembly of the seal to the shaft: (a) initial contact of the seal lip and shaft, (b) dust lip and shaft first contact, (c) contact stress at the end of the assembly operation.
Figure 4 shows the simulation of assembly operation for the lip seals on the radial shaft. As the result of this simulation, the residual radial force, deformed shape of the lip seals, maximum stress during assembly operation and assembled seals, maximum deflections on the seal lips were obtained. The residual radial force is significant to the performance of the seals, and this value should be optimized for the maximum seal lifetime. In Fig. 4, the FEA simulation of the assembly operation is presented. Figure 4a shows the equivalent von Mises stresses and shape of the seal lip at the beginning of the assembly. Figre $4 \mathrm{~b}$ shows the lip shape and maximum stress during assembly, and Fig. 4c shows residual stress on the seal lips after the assembly process. These stresses have an important influence on the fatigue and wear life of the radial shaft lip seals.

The first contact of the shaft with the elastomer can be seen in Fig. 4. The contact stress was then $0.285 \mathrm{MPa}$ (Fig. 4a). At the end of the analysis, the contact stress was $1.027 \mathrm{MPa}$. These stresses were very far away from the critical stresses of the material. $4 \mathrm{~mm}$ displacement on the $Z$-axis was realized.

\section{Conclusion}

In this study, the theoretical, experimental and finite element analysis of the rotary shaft seals were performed. The radial force of the lip seals was calculated and compared by analytical, experimental and finite element simulations. All results are in good agreement. The maximum equivalent stress, maximum displacement on the seal lip and lip shapes during the shaft assembly were also obtained. The conclusion of this study that the finite element analysis of the rotary shaft seals gives the critical information for the seal design such as seal lip shapes after assembly, radial forces for the sealing performance, maximum deflection and stresses for the performance estimation of the seals.

\section{References}

[1] F. Robert, Seals, and Sealing, 6th ed., Elsevier, Oxford 2014

[2] S.M. Zhou, P. Chen, Y. Shi, Procedia Eng. 130, 1000 (2015).

[3] Y. Yuan, C. Suan, L. Guo, F. Zhang, Eng. Fail. Anal. 45, 292 (2014).

[4] O. Calonius, M. Pietola, in: Proc. 6th JFPS International Symposium on Fluid Power, Tsukuba 2005, p. 328.

[5] L. Horve, Shaft Seals For Dynamic Applications, 1st ed., Marcel Dekker Inc., New York 1996. 